\title{
Metabolic Fate and Mechanism of Action of Chloroethylthiamine
}

\author{
II. Movement and Fate of Chloroethylthiamine along \\ Intestinal Lumen after Oral Administration to Chick
}

\author{
Hideyo Shindo, Toru Komai aNd EiIChi NaKaJima ${ }^{2}$
}

\author{
Central Research Laboratories, Sankyo Co., Ltd., \\ Shinagawa-ku, Tokyo (Post No. 140)
}

(Received December 27, 1971)

\begin{abstract}
The route of arrival of chloroethylthiamine at the cecal site after oral administration to chick was examined, as the drug is particularly active against Eimeria tenella which is parasitic in the cecal tissue. Macroautoradiography of chick whole gastrointestinal tract and the assay of radioactivity of various parts of the tract periodically after oral administration of ${ }^{35} \mathrm{~S}$-chloroethylthiamine indicated that chloroethylthiamine arrives and accumulates at the cecal site mainly by the passage through the digestive tract, in the highest concentration at about $8 \mathrm{hr}$ after administration. It was found that when administered into the ligated duodenal loop only a slight radioactivity was distributed in the cecal tissue. In addition, the most of radioactivity orally administered was found to be excreted into the urine during the first $5 \mathrm{hr}$ with the maximum rate between 2 and $4 \mathrm{hr}$, indicating that the urinary backflow is not participating in the accumulation in the ceca.
\end{abstract}

In the preceding paper (1), it was reported that chloroethylthiamine is absorbed well from chick intestine, mainly from the duodenum, even better than thiamine. Chloroethylthiamine is known to be particularly active against the cecal coccidium, Eimeria tenella, when administered to chicks as a feed additive (2). Therefore, assuming that a certain level of chloroethylthiamine at the cecal site is necessary for exerting the action, there might be three different possible pathways as a route of the drug arrival at the cecal site. The first possibility is the arrival through secretion of chloroethylthiamine from the circulating blood into the cecal tissue after being absorbed from the upper part of the intestine, the second is that through an urinary backflow of chloroethylthiamine from the cloaca after being excreted in the urine as suggested by Polin et al. (3) for Amprolium, and the third is that through a movement of chloroethylthiamine along the intestinal lumen down to the ceca, although a larger part might be absorbed during the movement. In the present paper, a series of experiments were carried out to evaluate which is the most important in participating actually among these three possibilities. The results indicated that after oral administration of chloroethylthiamine in chicks the drug is gradually accumulated in the ceca mainly through the movement of the drug along the intestinal lumen.

\footnotetext{
${ }^{1}$ Beclotiamine, Cocciden ${ }^{\circledR}$, Sankyo Co., Ltd.
}

2 進藤英世, 駒井 亭, 中島栄一 


\section{EXPERIMENTAL}

\section{Macroautoradiography of Whole Intes- tine of Chick}

Four male white leghorn chicks weighing about $250 \mathrm{~g}$ were fasted for $24 \mathrm{hr}$ and administered orally with $10 \mathrm{mg}{ }^{35} \mathrm{~S}$-chloroethylthiamine (specific activity: $0.83 \mu \mathrm{Ci} / \mathrm{mg}$ ) in $1.0 \mathrm{ml}$ saline solution into the crop by a stomach tube. One, 3, 6 and $8 \mathrm{hr}$ after the administration the whole gastro-intestinal tract was removed under ether anesthesia. The whole tract was then separated into two parts, one from the crop to the duodenum and the other from the upper end of the small intestine to the rectum, after ligation of the both ends. The tracts were embedded on microtome stages with methylcellulose gel and freezed in a mixture of acetone and solid carbon dioxide at about $-70^{\circ}$. Sections of $30 \mu$ thickness through the whole tract were obtained by tape-sectioning technique according to Ullberg (4). After drying the sections at $-10^{\circ}$, the autoradiograms were obtained after the exposure of the sections against Sakura Type N X-ray film for 12 days.

\section{Loop}

Experiments with Ligated Duodenal

In order to study the accumulation and/or secretion of chloroethylthiamine into the ceca from the circulating blood, ${ }^{35} \mathrm{~S}$-chloroethylthiamine was injected into the chick duodenal loop and the radioactivity in the ceca was determined. Six white leghorn chicks weighing about $400 \mathrm{~g}$ were used after fasting for $24 \mathrm{hr}$. A ligated loop of $10 \mathrm{~cm}$ length was prepared from the duodenum as described in the preceding paper (1) and $5 \mathrm{mg}$ of ${ }^{35} \mathrm{~S}$-chloroethylthiamine (specific activity: $3.62 \mu \mathrm{Ci} / \mathrm{mg}$ ) was injected into the lumen of the loop. Thirty minutes, 1, 3, 5 and $8 \mathrm{hr}$ after the injection, the chick was decaptured and the whole ceca, the duodenal loop and the upper, middle and lower parts of the small intestine in about $10 \mathrm{~cm}$ were removed after ligation of the both ends. Each intestinal section and the residual parts with the luminal contents were deproteinized and extracted twice with $15 \%$ trichloroacetic acid. The combined extracts were assayed for radioactivity with a
Packard Tri-Carb 3214 liquid scintillation counter.

Experiments on Distribution of ${ }^{35} S$ Chloroethylthiamine along Chick Gastrointestinal Tract

White leghorn chicks weighing 420 to 500 $g$ were used without starvation. Into the crop, $5.0 \mathrm{mg}{ }^{35} \mathrm{~S}$-chloroethylthiamine (specific activity: $1.44 \mu \mathrm{Ci} / \mathrm{mg}$ ) was administered by a stomach tube. One, 3, 5, 8 and $12 \mathrm{hr}$ after administration, the chicks were decaptured and the sections of $10 \mathrm{~cm}$ length were removed from various parts of the intestine in the same way as described above. The sections including the contents were extracted twice with $15 \%$ trichloroacetic acid and assayed for radioactivity. In the separate experiments to determine the radioactivity in the tissues, the contents of the intestinal section removed were washed out 5 times with $3 \mathrm{ml}$ portions of chilled saline before the extraction. In these experiments, the feces and urine were also collected periodically and were treated in the same way as the intestinal sections, to be assayed for radioactivity.

\section{Paper Chromatographic Separation of} ${ }^{35} S$-Substances

The radioactive extracts from the ceca were adsorbed on charcoal column treated with cholesteryl-stearate (5) and, after washing the column with $\mathrm{CO}_{2}$-free distilled water, eluted with $10 \%$ hydrochloric acid in propanol. After the eluate was concentrated in vacuo with rotary evaporator at $35^{\circ}$, the residue was spotted on Toyo Roshi No. 50 and separated by ascending paper chromatography for $40 \mathrm{hr}$ with the solvent system : tert. amylalcohol : $\mathrm{H}_{2} \mathrm{O}$ : $p$-toluene sulfonic acid $(60: 30: 2(\mathrm{v} / \mathrm{v} / \mathrm{w}))$. The radioactive spots were detected by paper chromatoscanner and the corresponding parts were cut, extracted with $0.1 \mathrm{~N}-\mathrm{HCl}$ and assayed for radioactivity.

\section{Experiments with Cecal Tissue Segments}

The tissue accumulation method used by Agar et al. (6) was used to study the uptake of ${ }^{35}$ S-thiamine by the cecal tissue. The chicks were anesthetized with ether and the ceca were quickly removed, everted over a glass rod and rinsed in chilled Krebs-Henseleit bicarbonate 
buffer (pH 7.4). Ten ring-shaped segments of 3 to $4 \mathrm{~mm}$ thickness were obtained from each everted cecum. The segments from 3 chicks were pooled and randomized to minimize the variability and 5 to 7 segments were incubated in $100 \mathrm{ml}$ Erlenmeyer flasks containing $15 \mathrm{ml}$ of Krebs-Henseleit bicarbonate buffer added with ${ }^{35}$ S-thiamine and chloroethylthiamine in an appropriate ratio. The medium was gassed with $95 \% \quad \mathrm{O}_{2}-5 \% \quad \mathrm{CO}_{2}$ before the incubation. After $30 \mathrm{~min}$ of incubation at $37^{\circ}$, the segments were rinsed with the buffer, blotted on a filter paper, weighed and extracted twice by homogenizing with $15 \%$ trichloroacetic acid. The combined extracts were assayed for radioactivity.

\section{REsults}

Macroautoradiography of Chick Whole Intestine

Autoradiograms of chick intestine 1, 3, 6 and $8 \mathrm{hr}$ after oral administration of ${ }^{35} \mathrm{~S}$-chloro-

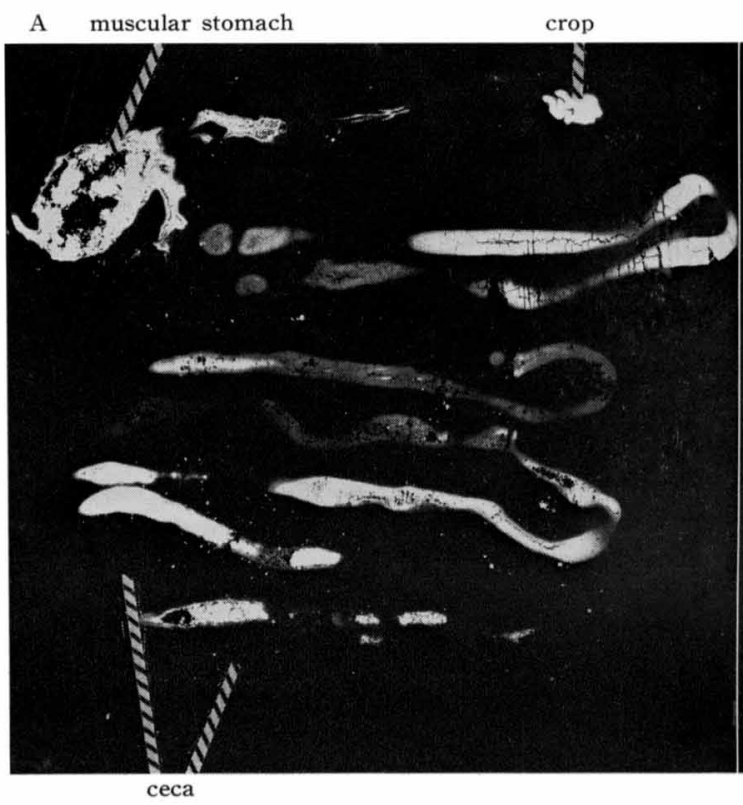

C
B crop muscular stomach

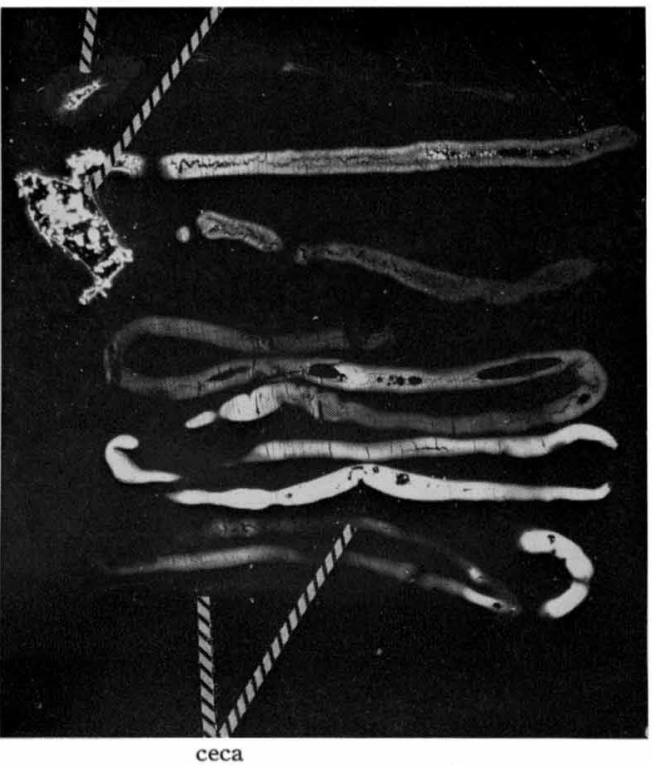

D

FIG. 1. Autoradiograms of radioactivity in chick gastrointestinal tract $1(A), 3(B), 6(C)$ and 8 hours $(D)$ after oral administration of ${ }^{35}$ S-chloroethylthiamine 
ethylthiamine were shown in Fig. 1. One hour after administration, the highest concentration of radioactive substance was observed at the part from the crop to the muscular stomach, while, although some radioactivity was detected in the lower part of the small intestine, no radioactivity was detected in the cecum. After $3 \mathrm{hr}$, a large amount of radioactivity was located at the site between the middle and the lower parts of the small intestine, while only a slight radioactivity was detected in the cecum. After $6 \mathrm{hr}$, on the other hand, the highest concentration was observed in the cecum with a lower concentration along the small intestine. After 8 $\mathrm{hr}$, the radioactivity was scarcely observed in the digestive tract except in the cecum where a high accumulation of radioactivity was still observed. These results suggest that chloroethylthiamine arrives at the ceca following a movement of the drug through the intestinal lumen within about $6 \mathrm{hr}$ after oral administration. Since chloroethylthiamine is easily absorbed from the duodenum and other part of the small intestine (1), however, a possibility that ${ }^{35} \mathrm{~S}$ substance was accumulated in the ceca by its secretion from the circulating blood after being absorbed can not be expelled. In order to examine this possibility, the following experiments were carried out.

Distribution of ${ }^{35}$ S-Chloroethylthiamine along Digestive Tract after Injection into Chick Duodenal Loop

${ }^{35} \mathrm{~S}$-Chloroethylthiamine was injected into the chick ligated duodenal loop and the amount of radioactivity were determined in the different part of the intestine including the cecum $1,3,5$ and $8 \mathrm{hr}$ after administration. The results were represented in Table 1 . The amount absorbed was calculated from the residual amount in the loop to be 65.7 and $98.5 \%$ of the dose 1 and $5 \mathrm{hr}$ after administration, respectively. In spite of this complete absorption, only a very small amount of ${ }^{35} \mathrm{~S}$-substance was found to be distributed in the ceca and other parts of the tract. The highest radioactivity in the ceca was found at $3 \mathrm{hr}$ after administration and was only 0.39 $\%$ of the dose. The total amount of radioactivity distributed in the whole digestive tract was $2.01,3.09,1.58$ and $0.70 \%$ of the dose $1,3,5$
TABLE 1

Distribution of radioactivity in chick intestinal tract after administration of ${ }^{35}$ S-chloroethylthiamine into ligated duodenal loop

\begin{tabular}{lcccc}
\hline \multirow{2}{*}{ Section } & \multicolumn{5}{c}{ hours after administration } \\
\cline { 2 - 5 } & \multicolumn{1}{c}{3} & 5 & 8 \\
\hline & \multicolumn{5}{c}{ per cent } & to dose \\
Duodenum & 34.29 & 17.50 & 1.49 & 0.41 \\
Small intestine & & & & \\
$\quad$ Upper & 0.81 & 1.01 & 0.55 & 0.12 \\
$\quad$ Middle & 0.03 & 0.11 & 0.07 & 0.12 \\
$\quad$ Lower & 0.13 & 0.07 & 0.07 & 0.03 \\
Ceca & 0.15 & 0.39 & 0.16 & 0.21 \\
Rectum & 0.95 & 0.35 & 0.27 & 0.46 \\
Whole digestive & 37.24 & 20.94 & 4.80 & 1.56 \\
tract & & & & \\
\hline
\end{tabular}

One $\mathrm{ml}$ solution of $5.0 \mathrm{mg}{ }^{35} \mathrm{~S}$-chloroethylthiamine was injected into the lumen of the ligated loop 18 $\mathrm{cm}$ long), after given times $8 \mathrm{~cm}$ sections or whole ceca were dissected from various parts of the intestine and the radioactivity determined.

and $8 \mathrm{hr}$ after administration, respectively. It might be evident from these results that the amount of chloroethylthiamine distributed in the ceca after being once absorbed is too small to play any significant role in its action against the cecal coccidium.

Distribution of ${ }^{35}$ S-Chloroethylthiamine along Digestive Tract after Oral Administration to Chicks

The distribution of radioactivity in the ceca and other part of the digestive tract after oral administration of $5.0 \mathrm{mg}{ }^{35} \mathrm{~S}$-chloroethylthiamine in chicks are shown in Table 2. After $1 \mathrm{hr}$ the highest amount of radioactivity was found to be present between the upper and the middle small intestine and only a very small amount, $0.18 \%$ of the dose, in the ceca. After $3 \mathrm{hr}$, the highest distribution of radioactivity was found between the middle and the lower small intestine and more than $2 \%$ of the dose was found to be arrived in the rectum, indicating a downward movement of ${ }^{35} \mathrm{~S}$-substance along the digestive tract. In accordance with this, the amount of radioactivity in the ceca was increased markedly after 3 and $6 \mathrm{hr}$, to about 3.8 and $6.4 \%$ of the dose, respectively, and attained to $10.8 \%$ of the dose $8 \mathrm{hr}$ after oral administration, when only a little radioactivity could be detected in any other part of the tract. 
TABLE 2

Distribution of radioactivity in intestinal tract and urinary excretion of radioactivity after oral administration of ${ }^{35} S$-chloroethylthiamine to chicks

\begin{tabular}{lrrrrr}
\hline \multirow{2}{*}{ Section } & \multicolumn{5}{c}{ hours after administration } \\
\cline { 2 - 6 } & 1 & 3 & 5 & 8 & 12 \\
\hline Duodenum & \multicolumn{5}{c}{ per cent to dose } \\
$\quad$ Upper & 1.77 & 1.20 & 0.54 & 1.29 & 0.48 \\
$\quad$ Lower & 1.83 & 1.06 & 0.40 & 0.36 & 0.37 \\
Small intestine & & & & & \\
$\quad$ Upper & 2.27 & 1.70 & 0.49 & 0.41 & 0.50 \\
$\quad$ Middle & 7.53 & 4.19 & 0.60 & 0.37 & 0.18 \\
$\quad$ Lower & 0.41 & 3.03 & 0.82 & 0.33 & 0.58 \\
Ceca & 0.18 & 3.76 & 6.36 & 10.83 & 4.07 \\
Rectum & 0.37 & 2.06 & 2.01 & 0.82 & 0.80 \\
Urine & 2.67 & 28.64 & 57.84 & 63.15 & 68.09 \\
\hline
\end{tabular}

$5 \mathrm{mg}{ }^{35} \mathrm{~S}$-chloroethylthiamine was administered orally, after given times $8 \mathrm{~cm}$ sections or whole ceca were dissected and the radioactivity determined. All values represent the average from 4 experiments.

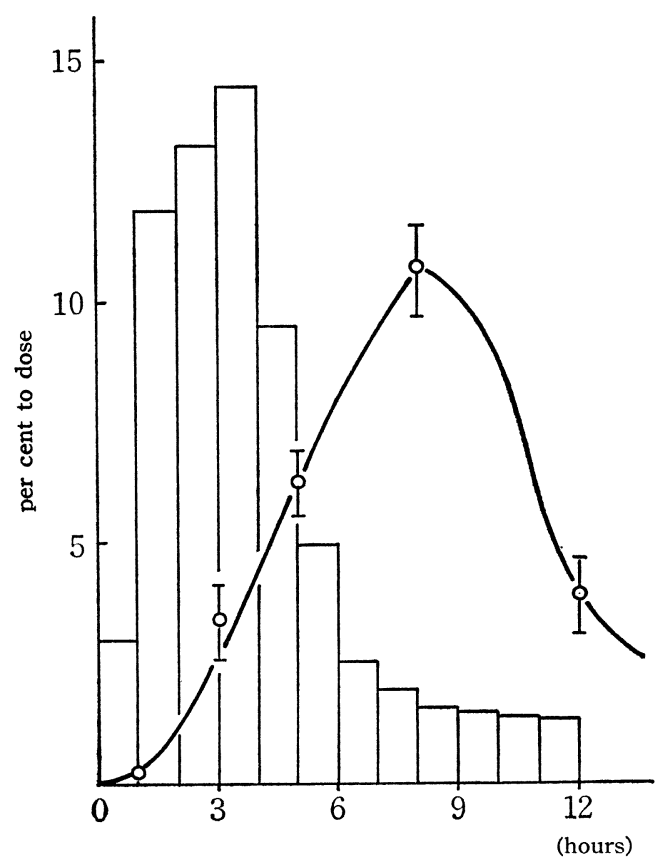

FIG. 2. Time-course of the cecal accumlation and the rate of urinary excretion after oral administration of ${ }^{35} \mathrm{~S}$-chloroethylthiamine

Five $\mathrm{mg}$ of ${ }^{35} \mathrm{~S}$-chloroethylthiamine was administered orally to chicks and the radioactivity excreted into urine and accumulated in ceca were determined periodically. The columns indicate the rate of urinary excretion and the curve indicates the cecal accumulation, as per cent of the radioactivity to dose.
The time course of the urinary excretion of radioactivity is shown in Fig. 2 in comparison with that of the accumulation in the ceca. It can be seen from the figure that the rate of excretion of radioactivity into the urine was maximum in the period between 2 and $4 \mathrm{hr}$ after the administration and about $58 \%$ of the dose was excreted within the first $5 \mathrm{hr}$ as compared with the total excretion of about 68 $\%$ of the dose in $12 \mathrm{hr}$. The facts that the amount of radioactivity in the ceca reached the maximum at $8 \mathrm{hr}$ after administration and, on the other hand, that the most of radioactivity administered was excreted into the urine before $5 \mathrm{hr}$ with the maximum rate between 2 and 4 hr might indicate that the accumulation of chloroethylthiamine and/or its metabolites in the ceca has no or little dependence upon those excreted in the urine.

\section{Metabolites in the Ceca}

${ }^{35} \mathrm{~S}$-Chloroethylthiamine and its metabolites in the ceca $8 \mathrm{hr}$ after oral administration in chick were separated by paper chromatography of the extracts. As shown in Fig. 3, several radioactive metabolites were detected. The main spot which was about $67 \%$ of the total cecal extracts was positive in the thiochrome reaction and the mobility on paper chromatography corresponded well to that of authentic chloroethylthiamine. Thus, it is indicated that the most of radioactivity arriving at the ceca after

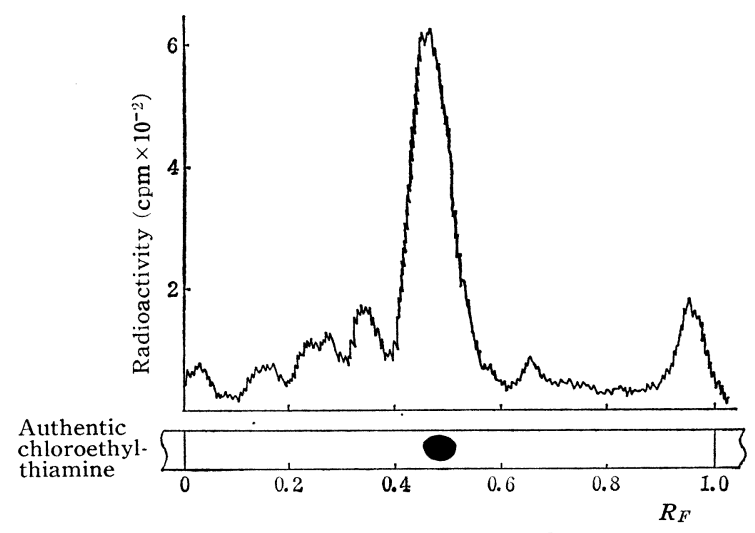

FIG. 3. Radioactigram of paper chromatogram of the cecal metabolites 8 hours after oral administration of ${ }^{35} S$-chloroethylthiamine

The solvent for PPC was tert-amylalcohol: water: p-toluene sulfonic acid $(60: 30: 2, \mathrm{v} / \mathrm{v} / \mathrm{w})$. 


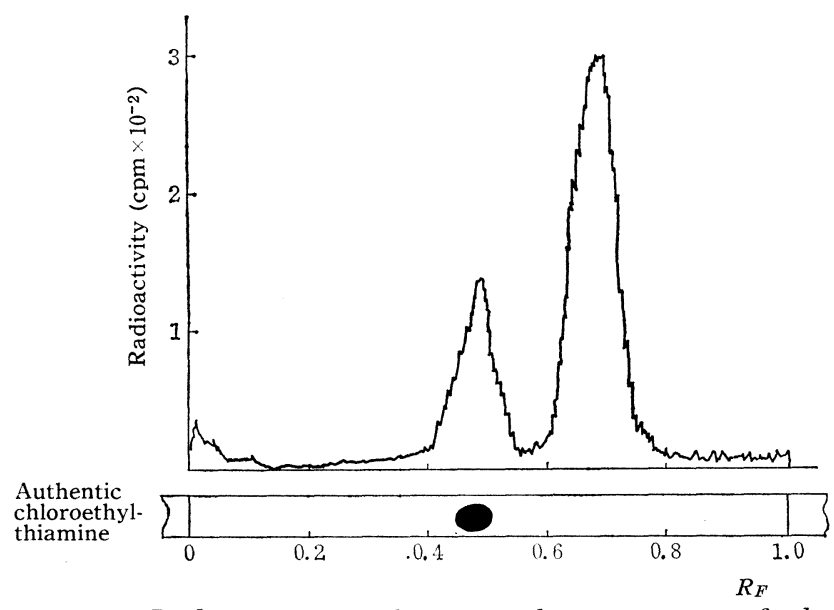

FIG. 4. Radioactigram of paper chromatogram of the cecal metabolites 1 hour after administration of ${ }^{35} S$-chloroethylthiamine into the ligated duodenal loop

oral administration is unchanged chloroethylthiamine.

The paper chromatogram of ${ }^{35} \mathrm{~S}$-substances in the ceca which were distributed in the tissue after being absorbed from the duodenal loop was significantly different from that after oral administration. As shown in Fig. 4, chloroethylthiamine was found to be less than $30 \%$ of the total extracts and over $70 \%$ was a metabolite which was negative in the thiochrome reaction.

From these results, it might be concluded that chloroethylthiamine administered orally arrives at the ceca mainly through its downward movement along the intestinal tract and exerts its action against the coccidium which is parasitic in the cecal epithelium.

Effect of Chloroethylthiamine on Thiamine Uptake by the Cecal Tissue

In the preceding paper (1), it was suggested as a possible mechanism of anticoccidium action of chloroethylthiamine that it might inhibit the thiamine uptake by coccidium which has a high nutritional requirement for thiamine (7). There are, however, two possibilities in the way of exerting this inhibition. One is that chloroethylthiamine inhibits directly the coccidium in taking up thiamine from the host cell and the other is that chloroethylthiamine inhibits thiamine uptake by the cecal epithelium and indirectiy prevents the thiamine uptake by coccidium.
In order to see the latter possibility, the effect of chloroethylthiamine on the thiamine uptake was examined by everted cecal segments. The results, as shown in Table 3 , revealed that no significant inhibition was observed with 5 to 100 times chloroethylthiamine to thiamine concentration of 1,10 and 100 $\mu \mathrm{g} / \mathrm{ml}$ medium. In addition, the ratio of the thiamine uptake to the initial thiamine concentration in the medium was $0.26,0.24$ and 0.21 for the concentration of 1,10 and $100 \mu \mathrm{g} / \mathrm{ml}$ medium, respectively, indicating that the uptake does not depend upon the initial thiamine concentration. From these results, it is indicated that the thiamine uptake by the cecal epithelium is proceeded by a passive diffusion and thus chloroethylthiamine does not inhibit the uptake. It might be more plausible, therefore, as a possible mechanism of the anticoccidium action that chloroethylthiamine inhibits directly the thiamine uptake by the coccidium from the host cell.

Chloroethyithiamine retained in the cecal tissue is thus considered to be of major importance in its anticoccidium activity and the distribution of ${ }^{35} \mathrm{~S}$-chloroethylthiamine in the intestinal and cecal tissue after oral administration was determined. As shown in Table 4, the amount of ${ }^{35} \mathrm{~S}$-substance in the cecal tissue reached the maximum at about $8 \mathrm{hr}$ after administration, in accordance with the increase in the lumen (Table 2). It was noted that the tissue from all parts of the intestine including

TABLE 3

Effect of chloroethylthiamine on uptake of ${ }^{35} S$ thiamine by everted cecal segments

\begin{tabular}{cccc}
\hline \multirow{2}{*}{ Cl- $\mathrm{B}_{1} / \mathrm{B}_{1}$ ratio } & \multicolumn{3}{c}{$\begin{array}{c}\text { initial thiamine concentration } \\
(\mu \mathrm{g} \text { per ml medium) }\end{array}$} \\
\cline { 2 - 4 } & 100 & \multicolumn{3}{c}{10} & 1 \\
\hline \multicolumn{4}{c}{$\mu$ thiamine per g-tissue } \\
0 & 21.33 & 2.432 & 0.258 \\
5 & 18.10 & 1.852 & 0.238 \\
10 & 20.03 & 2.308 & 0.231 \\
20 & 21.65 & 2.884 & 0.210 \\
100 & 17.57 & 2.645 & 0.209 \\
\hline
\end{tabular}

The segments were incubated at $37^{\circ}$ for $30 \mathrm{~min}$. Each value represents the average from 4 experiments. 
TABLE 4

Concentration of radioactivity in tissues from various parts of intestinal tract after oral administration of $8 \mathrm{mg}{ }^{35} \mathrm{~S}$-chloroethylthiamine to chicks

\begin{tabular}{lrrrr}
\hline \hline \multirow{2}{*}{ Section } & \multicolumn{5}{c}{ hours after administration } \\
\cline { 2 - 5 } & 1 & 3 & 6 & 8 \\
\hline & \multicolumn{5}{c}{$\mu$ g per } & g-tissue \\
Duodenum & 72.2 & 134.1 & 79.2 & 29.7 \\
Small intestine & & & & \\
Upper & 28.8 & 10.7 & 15.8 & 25.8 \\
Middle & 3.0 & 13.5 & 22.9 & 32.1 \\
Lower & 5.2 & 41.8 & 13.7 & 33.2 \\
Ceca & 3.9 & 17.0 & 19.4 & 27.1 \\
\hline
\end{tabular}

the ceca retained ${ }^{35} \mathrm{~S}$-substance in almost the same amount at this time after administration.

\section{Discussion}

From the present investigations, it was concluded that chloroethylthiamine administered orally to chicks arrives at the ceca mainly by the passage through the digestive tract and other possible pathways, that is, the urinary backflow suggested by Polin et al. (3), the excretion into the intestinal lumen after being once absorbed and the secretion into the cecal tissue from the blood circulation are all not participating to any significant extent. The concentration of chloroethylthiamine retained in the ceca was found to be much higher after in vivo oral administration than after in situ administration into the ligated duodenal loop. After $5 \mathrm{mg}{ }^{35} \mathrm{~S}$-chloroethylthiamine was orally given to chicks, the part of intestine with the highest concentration of radioactivity was demonstrated to move downward along the gastrointestinal tract with increasing the time and after $8 \mathrm{hr}$ the highest concentration was shown in the ceca, where the amount attained to 10.8 $\%$ of the dose (Table 2). On the other hand, after the administration into the ligated duodenal loop, the amount of radioactivity in the ceca attained to the maximum after $3 \mathrm{hr}$ and was only $0.39 \%$ of the dose (Table 1). In addition, after oral administration of ${ }^{35} \mathrm{~S}$-chloroethylthiamine to chicks the most of radioactivity was found to be excreted into the urine during the first $5 \mathrm{hr}$ with the maximum excretion rate between 2 and $4 \mathrm{hr}$. It is evident, therefore, that the rate of excretion into the urine is too fast to account for any participation of the urinary backflow in the accumulation of chloroethylthiamine in the ceca. This conclusion is in disagreement with that of Polin et al. (3) who concluded that the most of Amprolium arrived in the ceca was derived from the urinary backflow and the reason for the discrepancy is not well understood.

As a mechanism of anticoccidium action of chloroethylthiamine, a competitive inhibition of active transport of thiamine by chloroethylthiamine is considered to play an important role, as described in the preceding paper (1). From the present results, the thiamine uptake by the cecal tissue, i.e. the host cell of Eimeria tenella, was not inhibited by chloroethylthiamine. It is more plausible, therefore, to assume that chloroethylthiamine inhibits the thiamine uptake by Eimeria tenella from the host cecal cells competitively. After single oral administration of $8 \mathrm{mg}{ }^{35} \mathrm{~S}$-chloroethylthiamine, the content of chloroethylthiamine in the cecal tissue was in the order of 20 to $30 \mu \mathrm{g}$ per g-tissue. The thiamine content in the cecal tissue of the control chicks which were placed on normal diet was about 0.6 to $0.72 \mu \mathrm{g}$ per g-tissue. These results mean that chloroethylthiamine concentration becomes about 40 times higher than thiamine concentration and this ratio is considered to be enough to interfere significantly the thiamine transport, as revealed in the preceding paper (1).

\section{ACKNOWLEDGEMENT}

The authors express their deep gratitude to Dr. G. Sunagawa, director of this laboratories, for his valuable advices and encouragement. Thanks are also due to Dr. M. Nagawa and Mr. M. Kataoka of this laboratories for the preparation of ${ }^{35} \mathrm{~S}$-chloroethylthiamine, and to Mr. K. Nambu for his technical assistances.

\section{REFERENCES}

1. Shindo, H., and Komai, T., J. Vitaminol., 18, 41 (1972).

2. Inoue, I., Nomoto, S., Watanabe, F., and Suzuki, G., J. Japan Vet. Med. Asso., 20, 293 (1967).

3. Polin, D., Wynosky, E.R., Loukides, M., and Porter, C. C., Poultry Sci., 46, 88 (1967).

4. Ullberg, S., Acta Radiol. Supple., 118, 1 (1954).

5. Siliplandi, D., and Siliplandi, N., Biochim. Biophys. Acta, 14, 52 (1954).

6. Agar, W. T., Hird, F. J. R., and Sidhu, G. S., Biochim. Biophys. Acta, 14, 80 (1954).

7. Warren, E. W., Parasitology, 58, 137 (1968). 